\title{
Discriminación de bosques de Araucaria araucana en el Parque Nacional Conguillío, centro-sur de Chile, mediante datos Landsat TM
}

\author{
Discrimination of araucaria forests (Araucaria araucana) in the Conguillio National Park, \\ Southern-Center Chile, using Landsat TM data
}

\section{Nelson Ojeda a, c*, Víctor Sandoval ${ }^{\mathrm{b}}$, Héctor Soto ${ }^{\mathrm{a}}$, José Luis Casanova ${ }^{\mathrm{c}}$, Miguel A Herrera ${ }^{\mathrm{d}}$, Luis Morales ${ }^{\mathrm{e}}$, Alejandro Espinosa ${ }^{a}$, José San Martín ${ }^{\mathrm{f}}$}

\author{
*Autor de correspondencia: ${ }^{a}$ Universidad de La Frontera, Departamento de Ciencias Forestales, \\ tel.: 45-325652, fax: 45 - 325634, Temuco, Chile, nojeda@ufro.cl \\ ${ }^{\mathrm{b}}$ Universidad Austral de Chile, Instituto de Manejo Forestal, Valdivia, Chile. \\ c Universidad de Valladolid, Laboratorio de Teledetección, Valladolid, España.

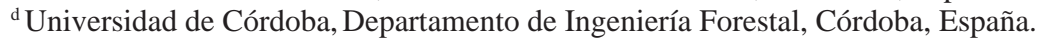 \\ e Universidad de Chile, Departamento de Ciencias Ambientales y Recursos Naturales Renovables, Santiago, Chile. \\ ${ }_{\mathrm{f}}^{\mathrm{f} U n i v e r s i d a d}$ de Talca, Instituto de Biología Vegetal y Biotecnología, Talca, Chile.
}

\begin{abstract}
SUMMARY
Araucaria forests (Araucaria araucana) have a tremendous ecological relevance; however, the information concerning their spatial distribution is still insufficient. They have only been classified according to small management scales, using satellite photos and images processed through conventional methods. The present study had as its objective to discriminate and characterize types of A. araucana forests in the Conguillío National Park, located in the Southern-Center Chile, through data derived from the Landsat-5 TM satellite and geographic information systems. The normalized difference vegetation index (NDVI) was satisfactorily related with variables corresponding to crown coverage and the diameter at breast height; thus, these index values were incorporated to the classification process. Using the digital elevation model and the NDVI, the effect provoked by the shadow was minimized. Seven types of forests, between dense and semi-dense-open, were discriminated in accordance with the accompanying species. The global reliability of the classification was $83.8 \%$. The greatest reliability for the producer was for the medium crown density forest of A. araucana $-N$. dombeyi (B1) (87.5\%); and for the consumer, for the high crown density forests of A. araucana - N. dombeyi (B1) and also for those of medium density (B2) (93\%). It is concluded that incorporating NDVI values and data derived from the digital elevation model to the satellite classification process, it is possible to discriminate araucaria forests with satisfactory reliability in areas of rough relief, which is very useful information for the management of these forestry ecosystems.
\end{abstract}

Key words: supervised classification, vegetation index, digital elevation model, araucaria forest, remote sensing.

\section{RESUMEN}

Los bosques de Araucaria araucana poseen gran relevancia ecológica, sin embargo su distribución espacial es poco conocida. Sólo han sido clasificados a escala pequeña, utilizando fotos e imágenes de satélite procesados con métodos convencionales. El presente estudio tuvo como objetivo discriminar y caracterizar tipos de bosques de A. araucana en el Parque Nacional Conguillío, localizados en el centro-sur de Chile, mediante datos derivados del satélite Landsat-5 TM y sistemas de información geográfica. El índice de vegetación de diferencia normalizada (NDVI) se relacionó satisfactoriamente con las variables cobertura de copa y el diámetro a la altura del pecho, por esta razón, se incorporaron valores de este índice al proceso de clasificación. A partir del modelo digital elevación y el NDVI se minimizó el efecto provocado por la sombra. Se discriminaron siete tipos de bosques, entre densos y semidensosabiertos, y de acuerdo con las especies acompañantes. La fiabilidad global de la clasificación fue de 83,8 \%. La mayor fiabilidad para el productor fue para el bosque de mediana densidad de copa de A. araucana-Nothofagus dombeyi (B2) (87,5\%) y para el consumidor, para los bosques de alta densidad de copa de A. araucana- $N$. dombeyi (B1) y también los de mediana densidad (B2) (93\%). Se concluye que incorporando valores NDVI y datos provenientes del modelo digital de elevación al proceso de clasificación satelital, es posible discriminar bosques de araucaria con fiabilidad satisfactoria en áreas de relieve abrupto, información muy útil para manejar estos ecosistemas boscosos.

Palabras clave: clasificación supervisada, índice de vegetación, modelo digital elevación, bosque araucaria, sensores remotos.

\section{INTRODUCCIÓN}

Existe una creciente necesidad por conocer mejor los ecosistemas boscosos en el mundo, utilizándose para este fin metodologías cada vez más refinadas, como las basadas en sensores remotos, las cuales generan nueva y potente información (Wright y Gallant 2007). Sin embargo, el uso de estas nuevas tecnologías no ha sido tan exitosa, por la 
dificultad que reviste clasificar los bosques debido, por un lado, a que grandes extensiones se distribuyen en áreas abruptas, y por otro lado, a la complejidad que reviste la presencia de distintas especies arbóreas dominantes en el estrato superior. En este sentido, se pueden producir confusiones espectrales entre especies forestales. Si bien es cierto, existen distintas maneras para clasificar los bosques naturales en el mundo, es necesario seguir probando nuevas metodologías basada en sensores remotos y que permitan una mejor caracterización y clasificación de ellos.

A nivel mundial, varios estudios han clasificado con cierto éxito los bosques basándose en su estructura y no en su composición. La presente investigación se basa en el primer criterio de clasificación. En este mismo contexto, Franklin (1994) compara distintos sensores para discriminar bosques. Los autores Jakubauskas y Price (1997) estratifican por estructura los bosques según el estado de desarrollo. También se puede caracterizar la estructura mediante la métrica vertical del bosque y su relación con imágenes satelitales. Por su parte Hall et al. (2006) modelan atributos de estructura de rodal. Como se mencionaba precedentemente, menos exitosas han sido las clasificaciones que se han basado en la composición de las especies determinando especies forestales.

En el caso de Chile, la aplicación de la tecnología de sensores remotos para el estudio de los bosques de Araucaria araucana (Mol.) K. Koch (araucaria) adquiere gran relevancia, ya que esta especie es reconocida mundialmente por su importancia como recurso biológico, como constituyente de una fuente genética única en el mundo, y también por su grado de endemismo y longevidad. En Chile, esta especie es declarada monumento natural y especie vulnerable. Además, desde el año 2000 A. araucana es incluida en el apéndice I de la convención del comercio internacional de especies amenazadas de flora y fauna.

En Chile, la mayor parte de los estudios que se ha desarrollado se centra en la vegetación nativa (matorrales, bosques, pastizales) más que en aplicaciones específicas en el bosque nativo, utilizando para ello complejos trabajos de fotointerpretación y generando cartografía de pequeñas escalas y, por lo tanto, información de menor grado de detalle. Entre estos estudios se encuentran aplicaciones en fitogeografía, fitoecología y bioclimatología. Las clasificaciones de bosques nativos son escasas y se basan en tipificaciones fisionómica-ecológica y estructurales-dasométricas (Donoso 1981).

Los estudios más recientes realizados en bosques nativos de Chile en los cuales se han utilizado sensores remotos, se centran en inventarios forestales. Otros han realizado clasificaciones parciales para estudiar la dinámica de cambios de la vegetación como aplicaciones en deforestación y fragmentación, paisajes de humedales, fragmentación de hábitat de especies amenazadas y determinación de variables de rodal y mortalidad.

Se puede aseverar que son escasas las aplicaciones de sensores remotos con el objetivo principal de clasificar bosques nativos en Chile, siendo uno de ellos el catastro de la vegetación natural de Chile, de cobertura nacional (CONAF-CONAMA-BIRF 1999); y la investigación propuesta por Segura y Trincado (2003) quienes aplican esta tecnología en la Reserva Nacional Valdivia.

Los estudios desarrollados localmente referidos a A. araucana tratan diversos aspectos de esta especie, como su dendrocronología, dinámica, regeneración, conservación, ecología, variación genética y silvicultura. Existe un estudio realizado en bosques de esta especie donde se aplican sensores remotos, pero con el objetivo de pronosticar variables de rodal, sin hacer referencia a la distribución espacial (Salas et al. 2010).

De los párrafos precedentes, se desprende la necesidad de contar con una metodología eficiente que sea adecuada y que permita con posterioridad inventariar regionalmente los bosques de A. araucana. Partiendo de la premisa que el índice de vegetación de diferencia normalizada (normalized difference vegetation index, NDVI) se relaciona bien con variables de estructura de los bosques (Lu et al. 2004), el presente estudio plantea como hipótesis que una clasificación supervisada basada en datos auxiliares provenientes del NDVI debe servir para generar una cartografía digital que discrimine satisfactoriamente los bosques de A. araucana. Consiguientemente, la presente investigación propone desarrollar una clasificación basada en la estructura de los bosques, planteándose como objetivo discriminar tipos de bosques de A. araucana en el Parque Nacional Conguillío, mediante datos derivados desde Landsat TM, y supervisando sus resultados mediante el uso de datos provenientes del índice de vegetación de diferencia normalizada. A partir de esta nueva información cartográfica, se espera contribuir a un mejor manejo de estos bosques y, por ende, a su conservación.

\section{MÉTODOS}

Área de estudio. Comprendió una superficie de 42.102 ha, equivalentes al $62,9 \%$ de la superficie total del parque, el cual se localiza en el centro-sur de Chile, en la Cordillera de Los Andes, entre las coordenadas geográficas $38^{\circ} 30^{\prime}$ a $38^{\circ} 50^{\prime} \mathrm{S}$ y $71^{\circ} 30^{\prime}$ a $71^{\circ} 55^{\prime} \mathrm{O}$, distante a $120 \mathrm{~km}$ de la ciudad de Temuco, región de La Araucanía. La altitud varió entre 700 y 3.125 m s.n.m. (figura 1).

Se utilizaron imágenes del satélite Landsat- 5 sensor TM, con fecha 30 de enero del año 2003. El área de estudio no ha sufrido eventos catastróficos volcánicos, como tampoco incendios forestales en los últimos años; por lo tanto, la información satelital reflejó bien la condición actual que existe en dicho parque. La resolución espacial del satélite fue de $27 \times 27 \mathrm{~m}$, y se georeferenció según el datum geodésico sudamericano (Chua - Brasil) (SAD-69) y Huso 18. La cartografía auxiliar utilizada fue la siguiente: límite del parque del ministerio de agricultura (escala 1:50.000), topografía (1:50.000), geología (1:250.000), 


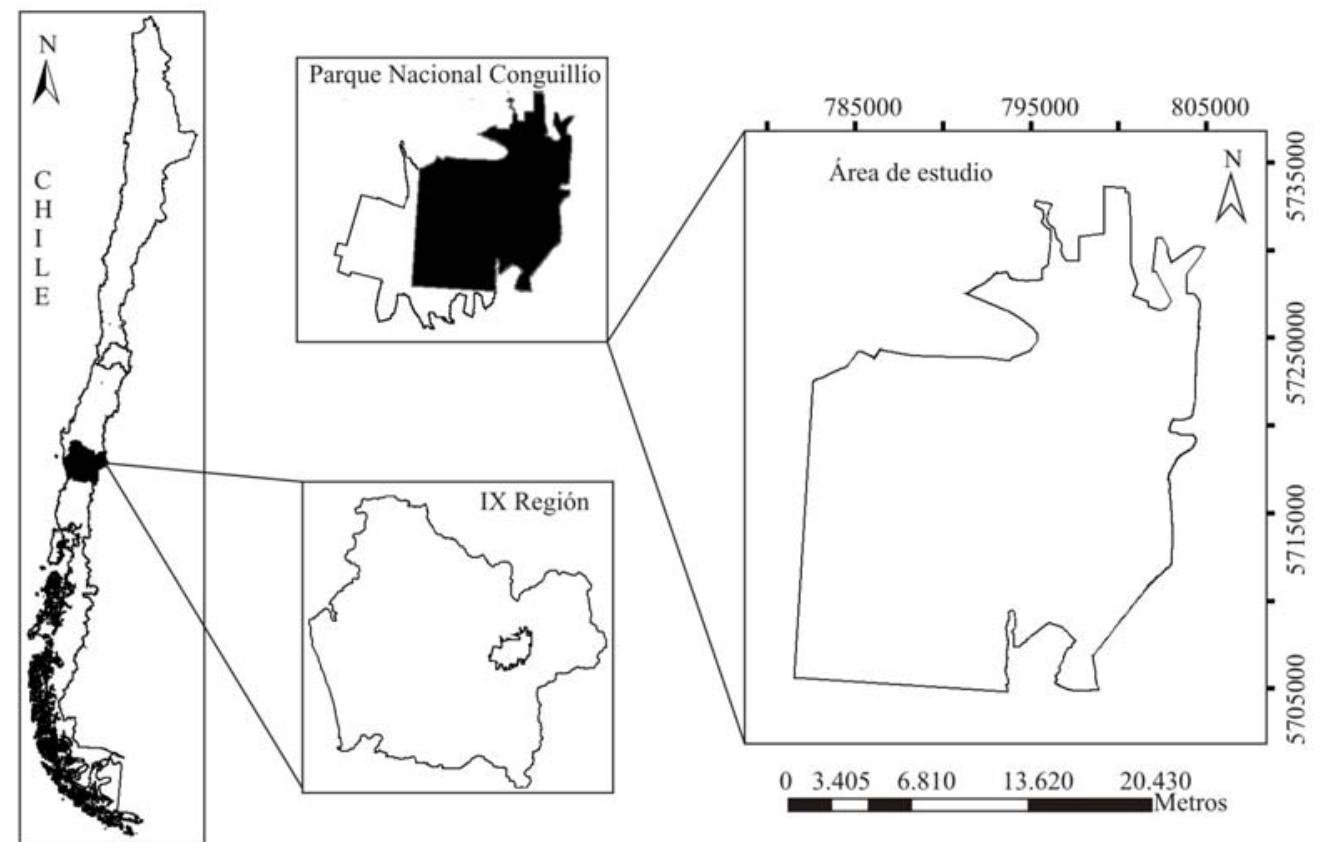

Figura 1. Área de estudio. Study area.

vegetación según SNASPE$^{1}$ (1:250.000), catastro y evaluación de recursos vegetacionales (1:250.000), mapa de zonificación Parque Nacional Conguillío (1:330.306), carta $\operatorname{IGM}^{1}(1: 50.000)$, fotografías aéreas digitales del año 2001 (1:115.000). Para el tratamiento de la información raster se utilizó el programa Idrisi Kilimanjaro y para la información vectorial, ArcGis versión 8.0. La supervisión en terreno se efectuó durante el mes de enero del año 2004. Con la finalidad de apoyar con datos de terreno georeferenciados la información proveniente del satélite, se utilizó el sistema de posicionamiento global marca Map 60CSx y una cámara digital Canon SX110, con lo que se obtuvo un total de 400 fotografías digitales.

Procesamiento de la imagen satelital. La corrección atmosférica se aplicó para reducir el incremento de la radiancia absorbida por el sensor. Los datos del sensor TM fueron convertidos a partir de sus valores niveles digitales (digital number, DN) a unidades de radiancia $(\mathrm{mW} / \mathrm{cm} 2 /$ sr / \# m). Se estimó esencial la incorporación de modelos topográficos debido a que en la zona estudiada predomina un relieve abrupto. El modelo de iluminación se derivó de un modelo digital de elevación (Riaño et al. 2003), el cual se utilizó para calcular el ángulo de incidencia respecto del sol, con curvas de nivel separadas cada 30 m [1]:

$$
I L=\cos \gamma_{i}=\cos \theta_{p} \times \cos \theta_{i}+\operatorname{sen} \theta_{p} \times \operatorname{sen} \theta_{i} \times \cos \left(\phi_{a}-\phi_{o}\right)
$$

\footnotetext{
${ }^{1}$ SNASPE: Sistema Nacional de Áreas Silvestres Protegidas del Estado (Chile). IGM: Instituto Geográfico Militar (Chile).
}

Donde,

$\theta_{p}$ : pendiente del terreno: la inclinación del terreno con respecto a la horizontal.

$\theta_{i}$ : ángulo cenital solar: el ángulo complementario de elevación solar.

$\mathrm{f}_{a}$ : ángulo azimutal solar: la dirección del sol con respecto al norte.

$\mathrm{f}_{o}$ : ángulo de orientación: el ángulo existe entre el vector que señala el norte y la proyección del plano horizontal del vector normal de la superficie en ese punto.

La reflectancia del plano normalizado de cada píxel, se obtuvo utilizando el método empírico estadístico, que es una variación del método no lambertiano (Meyer et al. 1993) [2]:

$$
P_{H}=P_{T} \times\left(\frac{\cos \theta_{i}+C_{k}}{I L+C_{k}}\right)
$$

Donde,

$P_{H}$ : reflectancia de la superficie horizontal.

$P_{T}$ : reflectancia de la superficie inclinada.

$\theta_{i}$ : ángulo cenital solar.

$C_{k}=b_{k} / m_{k}$ : cociente entre la pendiente y el término independiente $m_{k}$.

Para la corrección no lambertiana, fue necesario digitalizar áreas que presentaron condiciones similares de vegetación y cuya única diferencia se debió a variaciones 
de iluminación. Posteriormente, los polígonos se rasterizaron, generando a partir del modelo topográfico un mapa de iluminación (IL), el cual se calculó para cada píxel, considerando el ángulo del cenit y del azimut solar del sobrevuelo del satélite. De este modo, se obtuvo el valor $C_{k}$ para cada banda. Del análisis de regresión se obtuvo el valor $P_{T}$ para cada una de las bandas de la subescena. De este modo, las imágenes fueron corregidas topográficamente. Para confirmar que el proceso fue correcto, se efectuó un análisis de variabilidad espectral antes y después de la corrección topográfica. La integración de datos topográficos y satelitales se logró mediante el uso de un modelo digital de elevación, con el cual se catastró la vegetación y se ordenó según rango altitudinal, entre 850 y 1.750 m s.n.m., con equidistancia de $150 \mathrm{~m}$. La relación de las variables se efectuó mediante tabulación cruzada y se emplearon operaciones de lógica booleana.

Para estudiar la estructura de la vegetación y reducir el efecto causado por la sombra se construyó el índice de vegetación de diferencia normalizada. Este índice relacionó el vigor o estrés del bosque, el cual varía entre $-1 \mathrm{y}+1$. Su expresión matemática es la siguiente (Gilabert et al. 1997) [3]:

NDVI = (TM4-TM3)/(TM4+TM3)

Donde,

TM4: banda del infrarrojo cercano.

TM3: banda del rojo.

Clasificación digital. Se efectuó una selección de bandas mediante análisis de componentes principales, sobre seis de las siete bandas del sensor TM, excluyendo la banda térmica. De esta manera, se determinó la combinación de bandas lineales que eran independientes entre sí, y que reunían la información más valiosa. Los componentes principales se obtuvieron de la siguiente manera [4]:

$$
C P_{j}=\sum i=1, p a_{i},{ }_{j} D N_{i}+R_{j}
$$

Donde,

$\mathrm{CP}_{\mathrm{j}}$ : DN correspondiente al componente principal $\mathrm{j}$.

$a_{i, j}$ : coeficiente aplicado al DN de la banda i para generar el componente $\mathrm{j}$.

$\mathrm{R}$ : constante que suele introducirse en cada componente para evitar valores negativos.

Para realizar la clasificación supervisada y definir las categorías, se aplicó el sistema de clasificación jerárquica propuesto por Beaubien et al. (1999), referido al uso y cobertura del suelo, de gran utilidad para sensores remotos. Si bien este esquema de clasificación se publicó para su uso en EE.UU., su sistema puede aplicarse en diversos territorios. Con esta propuesta jerárquica, se clarificó el con- cepto de clasificación para estos bosques, por lo que se ordenó de acuerdo a la densidad de cobertura en: alta, media y baja. De este modo, las categorías formadas por "tipos de cubierta forestal" se denominaron en el texto tipos de "bosque" o "B". El proceso de clasificación se dividió en cuatro subtítulos, como se explica a continuación.

a) Clasificación preliminar digital y datos auxiliares de terreno. Primeramente, se registraron en terreno un total de 90 puntos de control (cada punto constatado en terreno, se georeferenció y fotografió para su posterior interpretación en laboratorio, chequeando esta información con los antecedentes auxiliares disponibles). La información auxiliar empleada correspondió al estudio CONAF/CONAMA/BIRF (1999) con cabida en el parque, fotografías aéreas, fotos digitales, generando posteriormente, a partir de la fotointerpretación, un mapa de verdad.

b) Clasificación y fase de generación de áreas de entrenamiento. Los puntos obtenidos en la primera fase de terreno se procesaron en el programa Idrisi Kilimanjaro como archivo raster, siendo la base para conocer el valor del índice de vegetación de diferencia normalizada individual asociado a cada punto. Siguiendo la metodología propuesta por Sesnie et al. (2008), con los valores de dicho índice se identificaron los valores medios de cada tipo de bosque; así posteriormente, con su valor mín-máx, la imagen fue reclasificada de acuerdo a la nueva información comprobada de terreno, descartando el resto de los valores del umbral asignado a otros usos, a base de esta nueva imagen reclasificada. Se extrajeron los niveles digitales (DN) asociados a cada tipo de bosque, esta información fue sobrepuesta sobre la imagen TM1, 2 y 3, con la cual se procedió a asignar las áreas de entrenamiento. El muestreo mínimo de píxeles fue superior a un $1 \%$ por categoría.

c) Fase de asignación y mapa temático. Para la clasificación se utilizó el algoritmo de máxima probabilidad, en el cual un píxel es asignado a la clase con la que posee mayor probabilidad de pertenencia.

d) Fase de comprobación y verificación. Para validar la clasificación, se comparó el mapa temático con el mapa de verdad. Este último, fue mejorado a base de una segunda fase de terreno, donde se añadieron 105 puntos sobre los 90 registrados durante la primera fase de terreno. El muestreo aplicado correspondió al aleatorio dirigido, debido a las condiciones de accesibilidad y zonas prohibidas al público. Con la finalidad de reducir el margen de error que se presenta entre la realidad y el mapa, fue necesario reajustar aquellos puntos de muestreo que cayeron muy cerca de los límites de los rodales. Mediante esta información se construyó un mapa de verdad en formato raster, el cual contuvo las 105 parcelas distribuidas espacialmente, y cada una tuvo asignación a un uso o categoría específica. 
Para evaluar la precisión de la clasificación que se derivó del mapa de verdad y el mapa temático, se empleó la técnica de análisis categórico multivariante kappa $(\kappa)$, ya que ha demostrado su eficacia para estudios de bosque nativo. De esta manera, se cuantificó el error y valoró su fiabilidad. Para el análisis estadístico se utilizó la matriz de confusión o matriz de error que recogió los conflictos que se presentaron entre los grupos de bosques. Para elaborarla se utilizó el mapa obtenido de la clasificación con el mapa de verdad derivado de los 105 puntos de verificación (utilizados en el muestro inicial para caracterizar las clases de bosques) e información de CONAF/CONAMA/BIRF (1999). Para esta comparación se aplicó el procedimiento establecido para el módulo ERRMAT de Idrisi. La medida del estadístico kappa $(\kappa)$ se obtuvo de la siguiente expresión (Hudson y Ramn 1987) [5]:

$$
\kappa=\frac{N \sum_{i=1, n} X_{i}-\sum_{i=i, n} X_{i+} X_{+i}}{N^{2}-\sum_{i=i, n} X_{i+} X_{+i}}
$$

Donde,

$X i i$ indica la coincidencia observada.

$X i+X+i$ : (producto de marginales) la coincidencia esperada.

$N$ : tamaño de la muestra.

Si todos los elementos que se encuentran fuera de la diagonal principal fueran iguales a cero, se tendría una concordancia completa $\kappa=1$. La diagonal de la matriz de confusión expresó el número de puntos de verificación donde hay coincidencia entre las dos fuentes (píxeles clasificados versus realidad), mientras que los marginales supusieron errores de asignación.

Medición y caracterización de la estructura de los bosques. Para efectuar las mediciones en terreno se utilizó un diseño de muestreo aleatorio dirigido, ya que proporcionó el mejor equilibrio entre la validez estadística y la aplicación práctica (Fitzpatrick-Lins 1981). De este modo, se obtuvo un mínimo de muestras por categorías para asegurar la representatividad (Landis y Koch 1977). Los criterios considerados en el muestreo fueron la variabilidad espacial, el tipo de bosque y su accesibilidad. Las 105 parcelas inventariadas presentan una dimensión equivalente al tamaño del píxel (Hall et al. 2006), dimensionado en $729 \mathrm{~m}^{2}(27 \times 27 \mathrm{~m})$. Según la resolución espacial las imágenes permiten trabajar a distintas escalas y precisión cartográfica. En este sentido, Jakubauskas (1996) demostró que un muestreo mínimo de 13 píxeles para Landsat $\mathrm{TM}$, generalizado a una hectárea, corresponde a superponer mapas escala 1:24.000. En este contexto, el número de parcelas se determinó, por un lado, con los criterios mencionados anteriormente, y por otro lado, que hubiese un mínimo de parcelas según tipo de bosque para garantizar la representatividad de las áreas entrenadas. En cada parcela se registró la especie, la altura total $(H$, en m), diámetro a la altura del pecho (dap en $\mathrm{cm}$ ), cobertura de copa ( $c c$, en $\%$ ); dichas mediciones se efectuaron sólo en árboles dominantes y codominantes. También se registró la altitud (m s.n.m.), exposición $\left({ }^{\circ}\right)$ y pendiente $(\%)$. La medición de altura total se efectuó sobre una muestra aleatoria entre 6-10 árboles por parcela, el resto se estimó mediante la confección de un modelo de regresión (Brokaw y Lent 1999). Los rangos de cobertura del estrato arbóreo, expresados en densidad, fueron: muy alta densidad de copa (100\%), alta densidad de copa (75-100 \%), mediana densidad de copa (50-75\%), baja densidad de copa (25-50 \%) y muy baja densidad de copa (0-25\%). Su determinación en terreno se efectuó por apreciación visual. Respecto al origen de los datos según las especies forestales, la información dasométrica provino de las especies arbóreas del bosque, y correspondió a: A. araucana, lenga (Nothofagus pumilio (P. et E.) Krasser), coigüe (Nothofagus dombeyi (Mirb.) Oerst.) y ñirre (Nothofagus antarctica (G. Forster) Oerst.). También provino de las coberturas de las especies de la familia Bambuceae, colihue (Chusquea culeou E. Desv.) y la Graminaceae, festuca (Festuca spp.).

Integración de los datos dasométricos e información satelital. Para esta tarea se utilizó el programa estadístico SPSS. Para ello, se aplicó el método de estimación de mínimos cuadrados ordinarios, estableciéndose un modelo de regresión lineal para cada variable respuesta cobertura de copa, altura total y dap, sobre una muestra de 74 parcelas, utilizándose como variable de predicción el índice de vegetación de diferencia normalizada (NDVI) asociado espacialmente a cada muestra. El modelo lineal simple se representa en la expresión [6]:

$y_{i}=\beta_{1}+\beta_{2} \chi_{i}+\varepsilon_{i} \quad i=1,2, . ., n$

Donde $y_{i}$ es el escalar que se corresponde a la observación i-ésima de la variable endógena del modelo, también denominado variable dependiente altura total (m) $y_{1}$, dap (cm) $y_{2}$, cobertura de copa (\%) $y_{3}$. De esta forma, $y=$ $\left(y_{1}, y_{2}, y_{3} \quad y_{n}\right)$ es el vector de dimensión $(n \times 1)$ que recoge todas las observaciones de la variable endógena del modelo. Por su parte, $\chi_{i}$ es la observación i-ésima de la variable explicativa, variable exógena del modelo (NDVI $\left.\left(\chi_{1}\right)\right)$. Así $\chi=\left(\chi_{1}, \chi_{2} \quad \chi_{n}\right)$ es el vector columna de dimensión $(n \times 1)$ que recoge todas las observaciones de la variable exógena del modelo. Por otra parte, como los coeficientes $\beta_{1} \beta_{2}$ son desconocidos, éstos fueron estimados de manera que el ajuste se aproxime lo más posible a los valores de $y_{i}$. El término $\varepsilon_{i}$ corresponde a la perturbación estocástica agregada al modelo para recoger todos los posibles errores de medida tanto en las variables 
e $\chi_{i} \quad y_{i}$ así como los errores en la especificación lineal del modelo (Grossman et al. 1996).

\section{RESULTADOS}

Se estima que los bosques (B1 a B7) se distribuyeron prácticamente en toda la superficie estudiada, localizándose entre 900 y 1.800 m s.n.m. de altitud. La mayor concentración de superficie de estos bosques se produjo entre 1.200-1.600 m s.n.m., siendo menor en los tramos 900-1.200 y 1.600-1.800 m s.n.m. (figura 2). Los bosques B1 alcanzarían la mayor distribución y, a la vez, la mayor cobertura de copa (A. araucana y Nothofagus spp.) dominando entre 1.500-1.600 m s.n.m. de altitud con 538,6 ha. Ecológicamente, es necesario destacar que el bosque de menor cobertura de copa (B7) mostró la segunda mayor distribución (2.503,9 ha). El bosque semidenso-abierto B7 se concentra en las mayores altitudes. Por su parte, el bosque B6 presenta una distribución discontinua entre las cotas máximas 1.400-1.700 m s.n.m.

Componentes principales y selección de bandas para la clasificación supervisada. Los autovalores extraídos en el proceso de selección de bandas fueron: 6.460,89; 1.034,88; 315,$47 ; 74,86 ; 10,36 ; 8,04$. Del análisis de autovectores el componente 1 mostró a la banda TM3 (rojo) como la que provee la información más provechosa para el estudio, le siguen las bandas TM1, TM2 y TM4.

Clasificación digital y fase de asignación. La distribución de los valores del umbral del índice de vegetación de diferencia normalizada (NDVI) asignados a cada grupo de interés, y su posterior asignación a los niveles digitales (DN) presentes en la imagen utilizada (TM1, 2 y 3), permitió diferenciar 20 clases espectrales. Posteriormente, mediante una reclasificación se redujeron a siete las clases temáticas.

En el cuadro 1 se observa el nombre de las categorías y en el cuadro 2 la información acerca de los píxeles en las áreas de entrenamiento e índice de vegetación. Se deduce que de la media de valores de referencia del índice de vegetación de diferencia normalizada, derivado de las parcelas de inventario, todos los grupos, excepto B5, estarían en un rango aceptable de dispersión de sus datos respecto a sus valores medios.

Análisis de las firmas espectrales. Las curvas exhiben una forma característica de la vegetación, de lo que se deduce la calidad de las áreas entrenadas (figura 3). La mayor diferencia de reflectancia espectral se observó entre la banda del rojo (TM3) y la de infrarrojo cercano (TM4), manteniéndose esa diferencia espectral, aunque en menor proporción, en las bandas del infrarrojo medio (TM5 y TM7). La curva más absortiva coincidió con el bosque de mayor cobertura de copa (80 \%) (B1). Los bosques B2, B5 y B7 (de menor cobertura de copa, $65 \%, 55 \%$ y $50 \%$, respec-
Cuadro 1. Nombre de las categorías según tipo de bosque de Araucaria araucana.

Category name according to the type of araucaria forest.

\begin{tabular}{|c|c|}
\hline Código & Tipos de bosque \\
\hline B1 & $\begin{array}{l}\text { Alta densidad de copa de A. araucana- } \\
N \text {. pumilio- } N \text {. dombeyi-sombra }\end{array}$ \\
\hline B2 & $\begin{array}{l}\text { Mediana densidad de copa de } \\
\text { A. araucana-N. dombeyi }\end{array}$ \\
\hline B3 & $\begin{array}{l}\text { Mediana densidad de copa de } \\
\text { A. araucana-N. dombeyi-N. pumilio }\end{array}$ \\
\hline B4 & $\begin{array}{l}\text { Mediana densidad de copa de } \\
\text { A. araucana- } N \text {. pumilio }\end{array}$ \\
\hline B5 & $\begin{array}{l}\text { Mediana-baja densidad de copa de } \\
\text { A. araucana-N. pumilio-Ch. } \text { culeou }\end{array}$ \\
\hline B6 & $\begin{array}{l}\text { Mediana densidad de copa de } \\
\text { A. araucana-N. pumilio achaparrado }\end{array}$ \\
\hline B7 & $\begin{array}{l}\text { Mediana-baja densidad de copa de } \\
\text { A. araucana-N. pumilio o N. antarctica } \\
\text { achaparrado-Festuca spp. }\end{array}$ \\
\hline
\end{tabular}

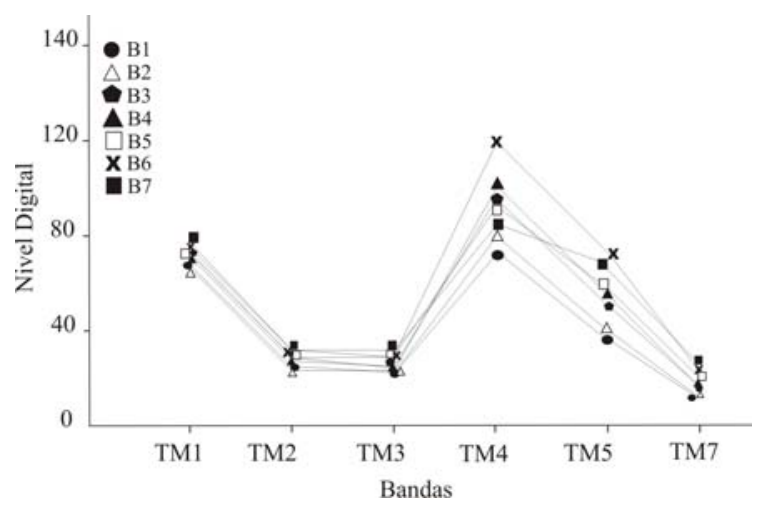

Figura 3. Firma espectral de las bandas originales del satélite Landsat-5 TM y los tipos de bosques de araucaria.

Spectral signature of the original bands of the Landsat-5 TM satellite and the types of araucaria forests.

tivamente) se localizaron en una zona intermedia; y el bosque B6 fue el más reflectivo, coincidiendo con su menor cobertura de copa.

Análisis del índice de vegetación de diferencia normalizada (NDVI). El bosque (B1) concentró los píxeles en los rangos de mayor vigor (figura 4), en cambio el bosque (B5), en los rangos de mayor estrés. En el tramo espectroradiométrico rojo e infrarrojo cercano, se separaron claramente los distintos tipos de bosques (figura 5). Por ejemplo, la curva con pendiente ascendente de B1 es más pronunciada y contrastó con B5. 

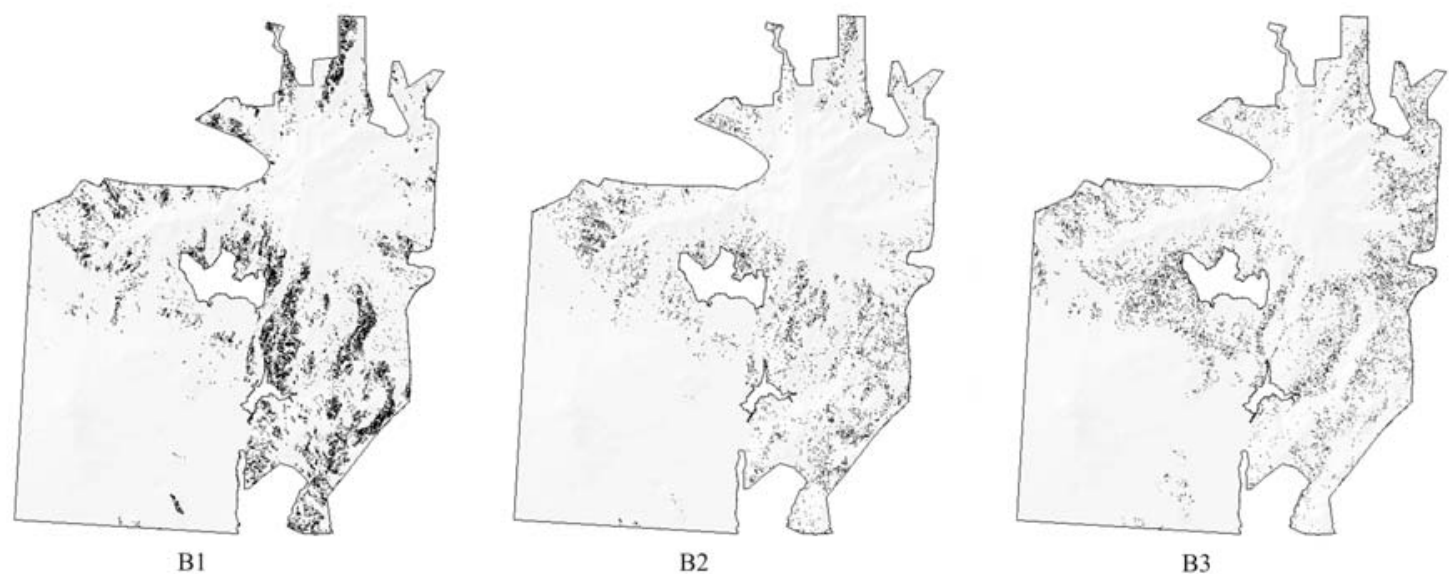

B2

B3
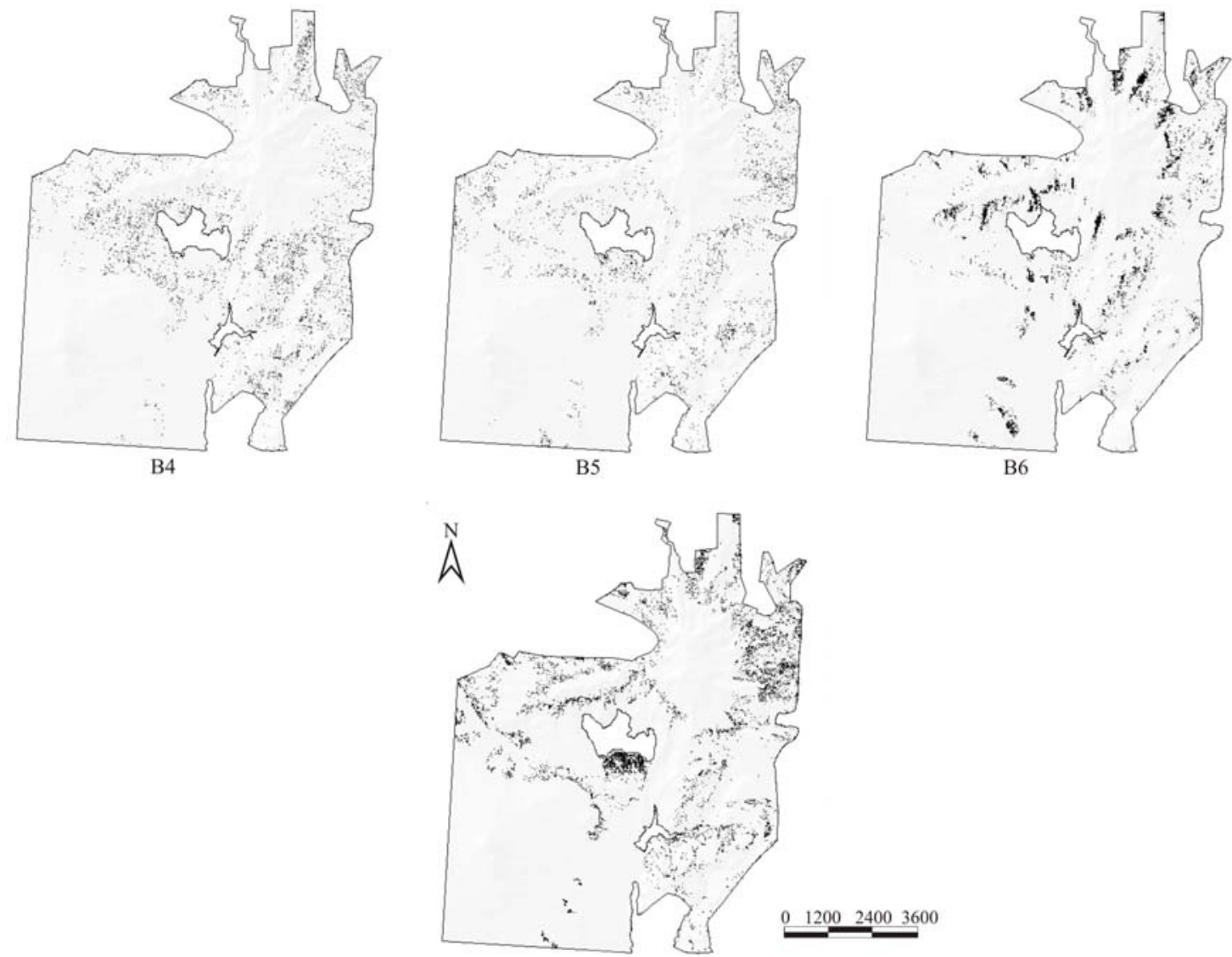

B7

Figura 2. Distribución estimada de tipos de bosques de araucaria B1, B2, B3, B4, B5, B6 y B7, a partir de la discriminación espectral derivada de imágenes Landsat-5 Thematic Mapper, en el Parque Nacional Conguillío.

Estimated distribution of types of araucaria forests B1, B2, B3, B4, B5, B6 and B7, from the spectral discrimination derived from the Lansat-5 Thematic Mapper images, in the Conguillío National Park. 
Cuadro 2. Píxeles correspondientes al área de estudio y al total de la clasificación supervisada, para cada tipo de bosque; y el número de píxeles muestreados en cada una de las áreas de entrenamiento. Se expone la proporción muestreada según cada tipo de bosque. Pixels corresponding to the study area and to the total of the supervised classification for each type of forest, and the number of pixels sampled in each one of the training areas. It presents the average sampled according to each type of forest.

\begin{tabular}{ccccrc}
\hline Código & $\begin{array}{c}\mathrm{N}^{\circ} \text { total de píxeles por } \\
\text { categoría }\end{array}$ & $\begin{array}{c}\mathrm{N}^{\circ} \text { de píxeles y áreas } \\
\text { de entrenamiento }\end{array}$ & $\begin{array}{r}\text { Proporción } \\
(\%)\end{array}$ & NDVI* & $\begin{array}{c}\mathrm{CV}^{* *} \\
(\%)\end{array}$ \\
\hline B1 & 47.684 & 3.853 & 8,1 & 0,6225 & 6,1 \\
B2 & 20.851 & 3.789 & 18,2 & 0,5814 & 9,6 \\
B3 & 27.653 & 4.188 & 15,1 & 0,6121 & 10,5 \\
B4 & 14.287 & 4.760 & 33,3 & 0,5521 & 18,5 \\
B5 & 12.511 & 4.298 & 34,4 & 0,4123 & 29,6 \\
B6 & 21.786 & 4.987 & 22,9 & 0,5753 & 12,2 \\
B7 & 35.212 & 4.120 & 11,7 & 0,4623 & 23,5 \\
\hline Total & 179.984 & 29.995 & 16,7 & - & - \\
\hline
\end{tabular}

*Media de valores del índice de vegetación de diferencia normalizada de referencia, proveniente de las parcelas de inventario. Los cuales sirvieron de base para perfeccionar posteriormente las áreas de entrenamiento. ${ }^{* *} \mathrm{CV}$ : coeficiente de variación de dicha muestra.

Cuadro 3. Registro de variables dasométricas de los bosque de Araucaria araucana. Las variables medidas corresponden a: cobertura de copa $(c c, \%)$, altura total $(H, \mathrm{~m})$ y diámetro altura del pecho (dap, $\mathrm{cm})$. Se expone la superficie que poseen (ha), la altitud (m s.n.m.) y la mayor concentración de su distribución según el rango de altitud (> m s.n.m.) de los bosques.

Dasometric variable registration of the araucaria forests. The variables measured correspond to: crown coverage ( $c c, \%)$, total height $(H, \mathrm{~m})$ and diameter breast height $($ dap, $\mathrm{cm})$. It presents the surface they have (ha), the altitude (m s.n.m.: $\mathrm{m}$, a.s.l) and the biggest concentration of their distribution according to the altitude range (> m s.n.m.: $>$ m, a.s.l.) of the forests.

\begin{tabular}{|c|c|c|c|c|c|c|c|c|c|c|}
\hline \multirow[b]{2}{*}{ Código } & \multirow[b]{2}{*}{$\begin{array}{l}\text { Superficie } \\
\text { (ha) }\end{array}$} & \multirow[b]{2}{*}{$(\%)$} & \multirow[b]{2}{*}{$\begin{array}{l}\text { Altitud } \\
\text { m s.n.m. }\end{array}$} & \multirow[b]{2}{*}{$\begin{array}{c}> \\
\text { m s.n.m. }\end{array}$} & \multirow[b]{2}{*}{$(\%)$} & \multicolumn{3}{|c|}{ Cobertura de copa $(c c, \%)$} & \multicolumn{2}{|c|}{ A. araucana } \\
\hline & & & & & & $\begin{array}{c}\text { A. araucana } \\
(\%)\end{array}$ & $\begin{array}{c}\text { Nothofagus spp. } \\
\text { y otras }(\%)\end{array}$ & $\begin{array}{l}\text { Total } \\
(\%)\end{array}$ & $\begin{array}{c}H \\
(\mathrm{~m})\end{array}$ & $\begin{array}{l}\text { dap } \\
\text { (cm) }\end{array}$ \\
\hline B1 & 2.626 & 25,4 & $1.000-1.700$ & $1.400-1.600$ & 39,1 & 35 & 45 & 80 & 22 & 78 \\
\hline B2 & 1.266 & 12,1 & $950-1.550$ & $1.300-1.400$ & 26,3 & 40 & 25 & 65 & 25 & 68 \\
\hline B3 & 1.440 & 13,8 & $1.650-1.550$ & $1.250-1.400$ & 48,5 & 35 & 35 & 70 & 24 & 75 \\
\hline B4 & 722 & 6,9 & $1.150-1.550$ & $1.350-1.450$ & 28,0 & 45 & 25 & 70 & 22 & 60 \\
\hline B5 & 583 & 5,6 & $1.250-1.650$ & $>1.400$ & 67,6 & 30 & 25 & 55 & 17,5 & 55 \\
\hline B6 & 1.292 & 12,3 & $1.000-1.700$ & $>1.400$ & 57,9 & 35 & 35 & 70 & 21 & 68 \\
\hline B7 & 2.505 & 23,9 & $1.000-1.750$ & $1.400-1.650$ & 48,8 & 20 & 30 & 50 & 18 & 55 \\
\hline Total & 10.463 & 100,0 & & & & & & & 21,4 & 65,6 \\
\hline
\end{tabular}

Caracterización estructural de los bosques. El bosque con mayor cobertura de copa obtuvo un promedio de $80 \%$, a diferencia de los más ralos que fluctuaron entre $50-55 \%$ (cuadro 3). Esta diferencia es significativa, ya que permitirá posteriormente diferenciar un tipo de bosque de otro. También la diferencia en altura fue importante, $17,5 \mathrm{~m}$ como promedio para el bosque más bajo (B5), y $25 \mathrm{~m}$ para el bosque más alto (B2). De estos resultados se desprende que los bosques presentaron diferencias significativas para distinguirlos desde imágenes satelitales. No ocurrió lo mismo al analizar los árboles individuales, ya que los radios de copas son similares entre los tipos de bosques. Éstos fluctuaron entre 3,6 y 4,5 m (B7 y B1, respectivamente). En el resto de los bosques se registraron radios de copas similares (entre 4 y 4,4 m).

El bosque B5 resultó ser uno de los más ralos. Su dosel es ocupado por A. araucana y Nothofagus spp. y en su cobertura de copa restante participaron Ch. culeou y otras especies (5-10 \%). De acuerdo a la observación satelital, los bosques B7 son semidensos-abiertos, es decir, con densidad de copa igual o inferior a un $50 \%$. La mitad de su cobertura está ocupada por Festuca spp., especie y cobertura que se hace más frecuentes en altitud.

Relación entre el índice de vegetación de diferencia normalizada (NDVI) y variables dasométricas. La estimación del valor medio de las variables dependientes cobertura de copa, dap y altura total con base en la variable explicativa índice de vegetación de diferencia normalizada (NDVI), mediante análisis de regresión (figura 6), indicó que todas las variables fueron estadísticamente significativas al analizar el valor $P$ del ajuste de los modelos. De acuerdo a la función estadística, el coeficiente de determinación general $\left(\mathrm{R}^{2}\right)$ explicó un $74,3 \%$ de la variabilidad de la cobertura de copa. El coeficiente de correlación de Pearson $r=0,861$, indicó una alta correlación positiva entre las va- 


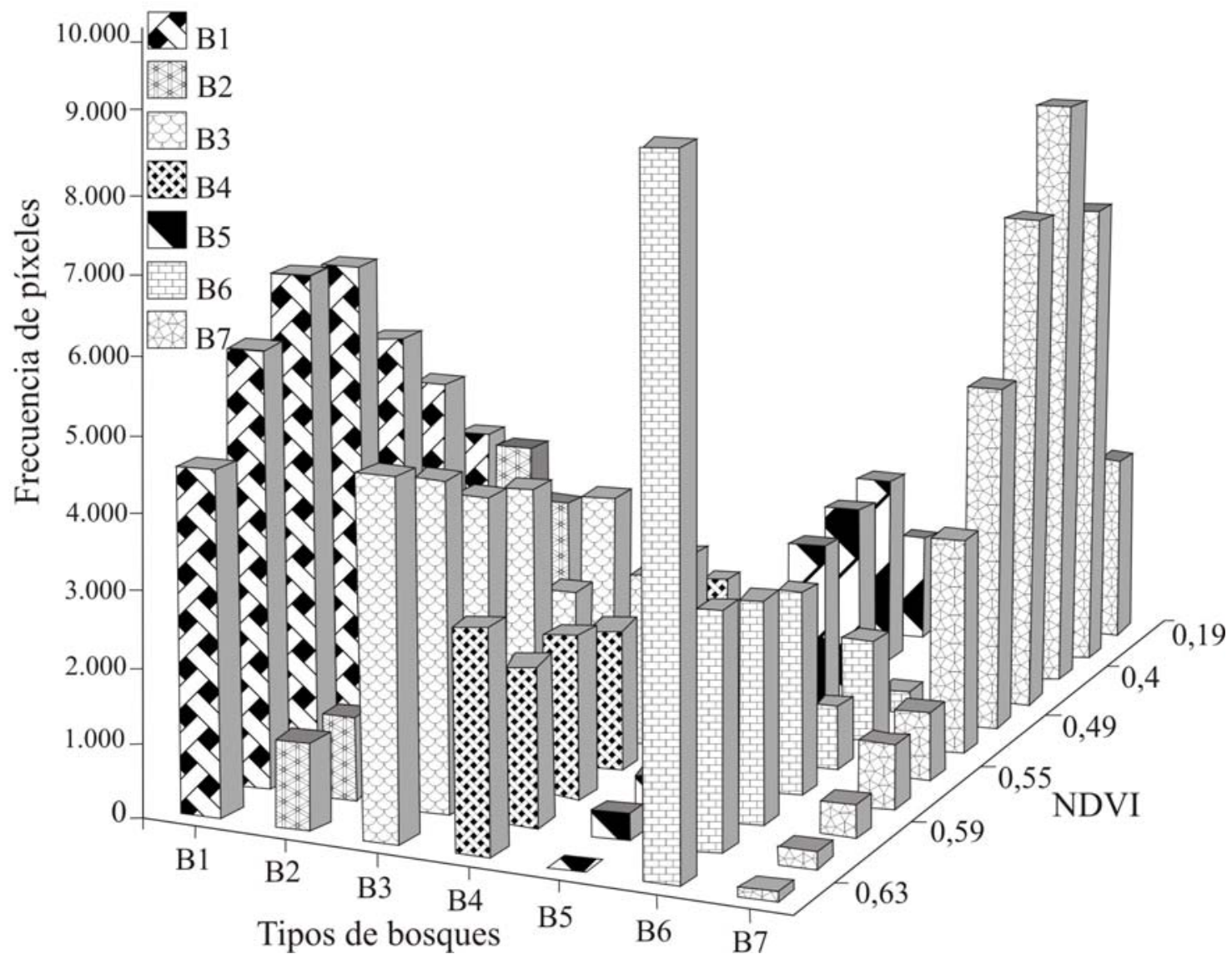

Figura 4. Distribución de la frecuencia de píxeles del índice de vegetación de diferencia normalizada (NDVI) derivado desde las áreas de entrenamiento, para cada tipo de bosque de araucaria.

Distribution of frequency of normalized difference vegetation index (NDVI) pixels derived from the training areas, for each type of araucaria forest.

riables. Para el dap se obtuvo un $\mathrm{R}^{2}=79,2 \%$, y la mejor correlación positiva, $r=0,89$. En el caso de la altura total, la función presentó un ajuste que explicó un $46,3 \%$ de la variabilidad, con $r=0,68$, indicando una correlación regular positiva entre las variables. Los errores estándares de estimación (ESE) de las funciones fueron: para la cobertura de copa, ESE = 4,41; para la altura total, ESE $=1,96$ y para el dap, $\mathrm{ESE}=3,62$. Con las 31 parcelas restantes, de un total de 105, el cálculo del error cuadrático medio (ECM \%) y de la diferencia agregada (DA \%) entregó los siguientes valores, respectivamente: en la cobertura de copas $2,51 \%$ y $5,52 \%$, en la altura total $7,12 \%$ y $16,16 \%$ y en el dap 2,36 \% y -1,64\%. Los valores del índice de vegetación de diferencia normalizada mostraron una buena relación con el dap y cobertura de copas, y menor con altura total. Debido a esta relación observada, la clasificación supervisada se efectuó a partir de datos provenientes del entrenamiento del índice de vegetación de diferencia normalizada. La importancia de la determinación de $\mathrm{R}^{2} \mathrm{y}$ $r$ en este estudio, es que aparte de los datos obtenidos en laboratorio, se analizaron datos de terreno, aplicación poco frecuente en estudios con sensores remotos, donde es difícil contar con este tipo de información.

El estadístico kappa $(k)$, se calculó para un nivel de confianza de $95 \%$ y un error admisible del $10 \%$, con 105 puntos muestreados (cuadro 4). Para el cálculo de la fiabilidad se estudió la significación de la diferencia, para un nivel $\alpha=0,05$, le correspondió un $Z$ crítico de 1,96. El error estándar de estimación (ESE) fue de 0,995. Las fiabilidades por tipo de bosque fueron similares, sólo se diferenció B7 para el "consumidor" que fue menor (71 \%).

\section{DISCUSIÓN}

Lo que complica la discriminación de los bosques de A. araucana en su distribución natural es un relieve marcadamente abrupto; por ello, es necesario incorporar variables auxiliares para poder estimar su distribución espacial mediante imágenes de satélite. La incorporación de valores del índice de vegetación de diferencia normalizada 


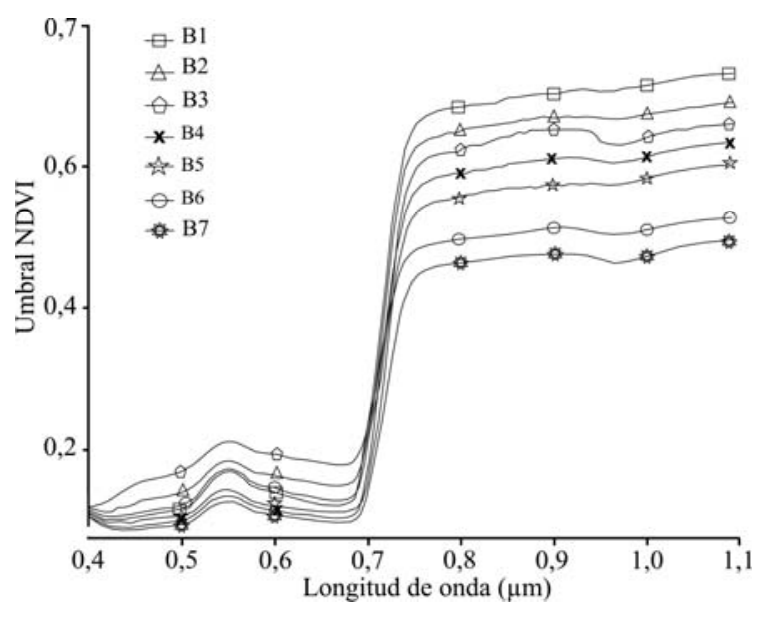

Figura 5. Curvas de tendencia de las áreas de entrenamiento derivadas del índice de vegetación de diferencia normalizada (NDVI), para los tipos de bosques de araucaria. Las curvas muestran el espectro electromagnético correspondiente a este índice, entre los tramos visible $(0,4 \mu \mathrm{m})$ y el infrarrojo cercano $(1,1 \mu \mathrm{m})$, de longitud de onda.

Tendency curves of the training areas derived from normalized difference vegetation index (NDVI), for the types of araucaria forests. The curves show the electromagnetic spectrum corresponding to this index, between the visible range $(0.4 \mu \mathrm{m})$ and the near infrared $(1.1 \mu \mathrm{m})$ of the wavelength.

(NDVI) al proceso de clasificación supervisada, y el modelo digital de elevación para reducir el efecto provocado por la sombra, fueron determinantes para el buen resultado obtenido en la clasificación al interior del parque.

Existen distintos criterios para clasificar la vegetación en el mundo, los cuales permiten discriminar según diferencias significativas entre grupos con características distintas, y el método que se utilice orientará la interpretación que se hace de ella. En este contexto, se optó por clasificarlos jerárquicamente en "forma general vegetativa", es decir, por estructura. En este sentido, Beaubien et al. (1999) han demostrado su utilidad discriminando bosques boreales según densidad de copas.

Para mejorar el proceso de clasificación se incorporó al análisis un modelo digital de elevación, donde el estadístico kappa arrojó un valor de $81,1 \%$, resultado que es considerado fiable y explicado, en parte, por la incorporación del modelo topográfico. En este sentido, la utilización del modelo se justifica por el hecho que la vegetación se encuentra estructurada en rangos de altitud, y por lo tanto, las variables derivadas del modelo son utilizadas como descriptoras de la distribución espacial. Aunque en el presente estudio no se evaluaron resultados con y sin la incorporación del modelo, de la topografía del área de estudio y lo planteado por varios autores, se infiere que el resultado obtenido se debe a la aplicación de este modelo
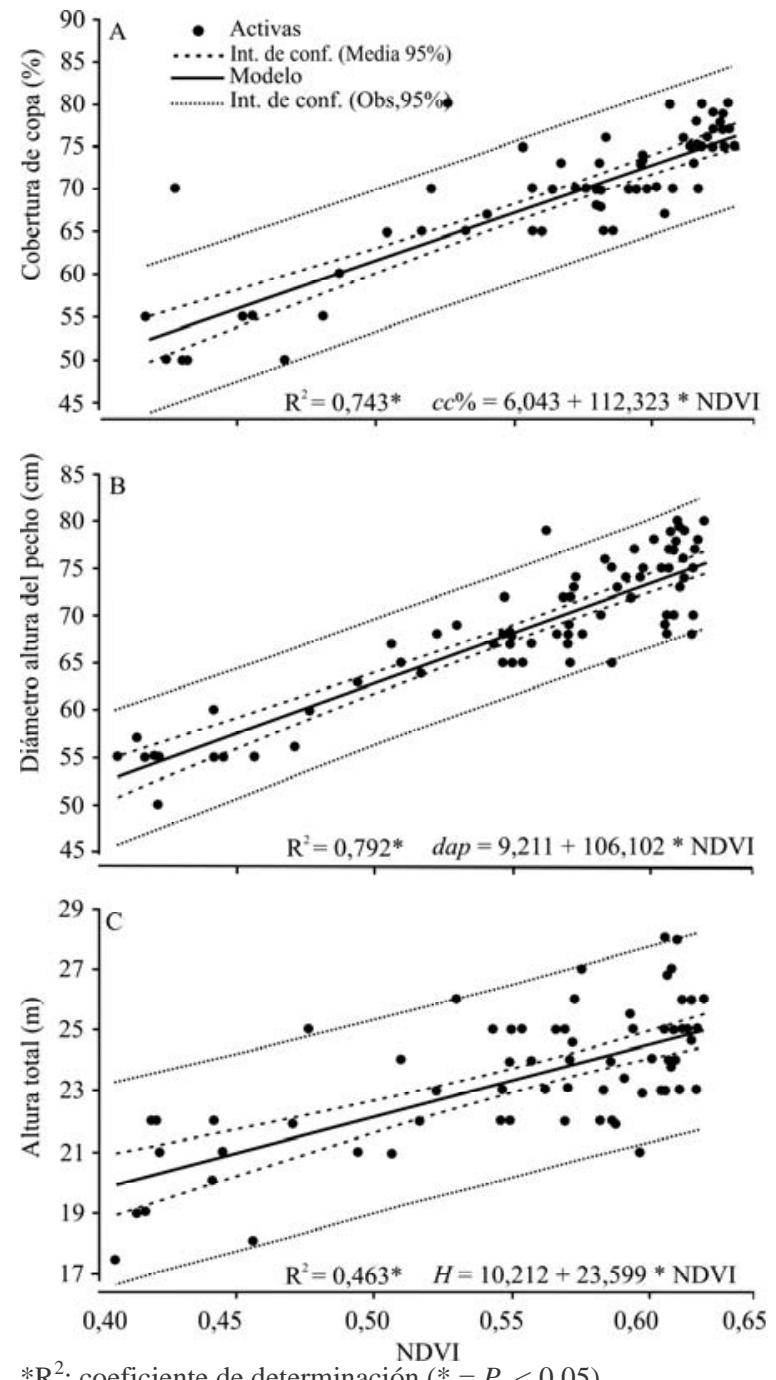

$* R^{2}$ : coeficiente de determinación $(*=P<0,05)$.

Figura 6. Relación entre el índice de vegetación de diferencia normalizada (NDVI) y tres variables dasométricas de los tipos de bosque de araucaria: a) NDVI y la cobertura de copa ( $c c$, en $\%$ ), b) NDVI y el diámetro altura del pecho (dap, en $\mathrm{cm}$ ) y c) NDVI y la altura total de los árboles $(H$, en $\mathrm{m})$. Para una muestra poblacional de terreno $n=74$ parcelas.

Relation between the normalized difference vegetation index (NDVI) and three dasometric variables of the types of araucaria forest: a) NDVI and crown coverage (cc, \%), b) NDVI and diameter breast height $(d a p, \mathrm{~cm})$, and c) NDVI and total height of the trees $(H, \mathrm{~m})$. For a ground population sample, $n=74$ plots.

conceptual. En el mismo contexto, Shupe y Marsh (2004) reafirman lo planteado anteriormente, y también en relieve abrupto ellos demuestran la eficacia del modelo reportando una primera clasificación en bosques-matorrales con un kappa de 56,12\%, la cual al incorporar posteriormente el modelo, kappa se elevó a un 81,86 \%. Por su parte, Salovaara et al. (2005) en zonas de difícil acceso en la amazonía peruana, lograron óptimas clasificaciones integrando datos Landsat ETM+ y un modelo STRM. En este contexto, la metodología utilizada en la presente investigación, en la 
Cuadro 4. Matriz de confusión de las siete categorías o tipos de bosques de Araucaria araucana.

Confusion matrix of the seven categories or types of araucaria forests.

\begin{tabular}{ccccccccccc}
\hline Código & B1 & B2 & B3 & B4 & B5 & B6 & B7 & Total & $F p$ & $E c$ \\
\hline B1 & 13 & - & - & - & 1 & - & 2 & 16 & 81,2 & 18,8 \\
B2 & - & 14 & 2 & - & - & - & & 16 & 87,5 & 12,5 \\
B3 & - & 1 & 13 & - & - & - & 1 & 15 & 86,7 & 13,3 \\
B4 & 1 & - & - & 12 & 1 & - & - & 14 & 85,7 & 14,7 \\
B5 & - & - & - & 2 & 11 & 1 & - & 14 & 78,5 & 21,5 \\
B6 & - & - & - & - & 2 & 13 & 2 & 17 & 76,4 & 23,6 \\
B7 & - & - & - & - & - & 1 & 12 & 13 & 92 & 8 \\
\hline Total & 14 & 15 & 15 & 14 & 15 & 15 & 17 & 105 & - & - \\
FC & 93 & 93 & 87 & 86 & 73 & 87 & 71 & - & - & - \\
Eo & 7 & 7 & 13 & 14 & 27 & 13 & 29 & - & - & - \\
\hline
\end{tabular}

Los valores $E o, F c, E c$ y $F p$ se expresan en porcentaje (\%). Eo: error por omisión; Ec: error por comisión; $F c$ : fiabilidad consumidor; $F p$ : fiabilidad productor. Total puntos de muestreo: 105; total puntos de concordancia: 88; fiabilidad global de la clasificación (\%): 83,8; valor de kappa (\%): 81,1.

cual se utilizan datos de exposición y pendiente derivados del modelo, para supervisar la clasificación y reducir, a la vez, el efecto causado por la sombra, sin duda mejoran el resultado final, y además, puede sugerirse su replicación a otras zonas con relieve abrupto, como es el caso de las cordilleras de la Costa y Los Andes en Chile y en otras latitudes.

Al comparar el estadístico kappa de 81,1\% obtenido aquí con otras clasificaciones, éste debe considerarse óptimo, ya que en otras partes del mundo se han clasificado bosques complejos, con un $55 \%$ de fiabilidad, considerándose buenos resultados. El autor Apan (1997) ha estudiado bosques tropicales complejos con una fiabilidad de $66,7 \%$ para el usuario y $56,6 \%$ para el productor. Por su parte, Liberti et al. (2009) discriminan bosques con una precisión global entre $53 \%$ a $72 \%$. En este contexto, el buen resultado obtenido en la clasificación de bosques de A. araucana, se explica, en parte, por su estructura menos compleja que otros bosques, con menos estratos y variedad de especies, lo que deriva finalmente en una mejor discriminación.

La clasificación expuesta obtuvo estrecha relación entre la estructura de los bosques de A. araucana y sus valores digitales en la imagen. En este contexto, Shupe y Marsh (2004) coinciden, al igual que el presente estudio, en sus buenos registros de correlaciones con la media de la cobertura de copa de los árboles. Del mismo modo $\mathrm{Lu}$ (2005) clasificó bosques en la amazonía, utilizando para ello la media de la variable de distribución de altura total, y la diferencia con la presente investigación se produce en que la relación con la altura fue más negativa. Por su parte Wright y Gallant (2007) demuestran la utilidad de las variables cobertura de copa y densidad y clasifican humedales en el parque nacional Yellowstone.

Por lo general, para clasificar la vegetación, metodológicamente se ha recurrido a datos provenientes de bandas originales. Sin embargo, en estudios recientes se han incorporado índices de vegetación al proceso, debido a que estos son independientes de los efectos causados por sombras. En este sentido, Solans y Barbosa (2010) reconocen que el índice de vegetación de diferencia normalizada es un índice ya aplicado, pero que demuestra estrechas relaciones con las variables de estructura. En la presente investigación, se confirma este planteamiento, ya que se registraron buenas relaciones entre los valores de dicho índice con cobertura de copa y dap $\left(\mathrm{R}^{2}=0,74\right.$ y $\mathrm{R}^{2}=0,79$, respectivamente), por lo que la discriminación respondería a estos atributos del bosque y que, por lo tanto, el índice de vegetación de diferencia normalizada es un aporte a la fiabilidad de la clasificación. La metodología que se presenta es innovadora en Chile, ya que se utilizaron las bandas originales, a lo cual se sumaron valores del índice de vegetación de diferencia normalizada con su correspondiente posición geográfica. Del mismo modo, Sesnie et al. (2008) también incursionaron con un método extrayendo valores de este índice, pero donde el índice es considerado como una banda más en el proceso. Por su parte, Sesnie (2008) también valora el método y reporta, al igual que la presente investigación, que cobertura de copa es una de las variables más relacionadas con el índice de vegetación de diferencia normalizada. Por su parte, Sebem et al. (2005) también clasifican a partir de las bandas originales, pero la supervisión la realiza a partir del histograma de este índice. Un tratamiento diferente de los valores del índice de vegetación de diferencia normalizada los reporta Giannetti et al. (2001) y Campo et al. (2004), quienes generan capas digitales a partir de valores medios de cobertura del índice.

En Chile se han realizado estudios en la región de La Araucanía con el objetivo de clasificar el bosque nativo, utilizándose para ello sólo métodos convencionales de clasificación desde bandas originales (CONAF-CONAMABIRF 1999). Por su parte, Segura y Trincado (2003), en la Reserva Nacional Valdivia, innovan incorporando valores del índice infrarrojo de diferencia normalizada (normalized difference infrared index, NDII) para clasificar vegetación natural. A diferencia de los estudios expuestos, en la 
presente investigación el proceso utilizado para reducir el efecto de la sombra fue más completo, ya que se incorporaron datos provenientes del modelo digital de elevación y los del índice de vegetación de diferencia normalizada, este último también minimizador de dicho efecto negativo.

Normalmente, el muestreo de terreno es difícil de realizar en zonas con relieve abrupto. Con esta motivación, Fitzpatrick-Lins (1981) calculó el tamaño de la muestra para evaluar el uso de la tierra, deduciendo que 319 muestras son suficientes para determinar 30 categorías, con una precisión de un $85 \%$ y un error admisible del $4 \%$. Por su parte, Jakubauskas (1996) utiliza para árboles adultos parcelas de $20 \times 25 \mathrm{~m}$ y para los árboles jóvenes de $10 \times 10 \mathrm{~m}$. En este contexto, el tamaño utilizado aquí de $27 \times 27 \mathrm{~m}$ es satisfactorio, aunque un mayor tamaño de parcela representará mejor los ecosistemas boscosos. Respecto a la intensidad de muestreo, Jakubauskas y Price (1997) registraron 69 muestras para 10 clases de cobertura espectral. En el presente estudio, el muestreo fue de 105 parcelas para siete tipos de bosques, lo que de acuerdo al autor citado precedentemente, puede considerarse como un muestreo adecuado. Contrario a esta afirmación Salovaara et al. (2005) estudiando bosques inundados y de tierra firme, logran resultados notables al aumentar la intensidad de muestreo. Se ha demostrado también que la importancia del uso de sensores remotos, es que con métodos simples y datos mínimos, se puede obtener una clasificación representativa de bosques constituidos por distintas especies.

En el estudio que se expone el bosque más entrenado correspondió a B5, y puede ajustarse al criterio de equivalencia de 1 ha; en cambio, para los menos entrenados (B1 y B7), la discriminación mínima se asume de 6,25 ha. En este contexto, el plan de manejo del parque se elabora a una escala 1:330.306. Si bien la cartografía que presentan estos bosques de A. araucana está a escala pequeña, cumple con los objetivos de conservación al interior de áreas silvestres, como es el caso del Parque Nacional Conguillío. Sin embargo, la discriminación de tipos de bosques que aquí se propone, a una escala más grande, mejora el manejo en este tipo de áreas. Un ejemplo de manejo que se desprende de los resultados, es que el bosque B7 que es un bosque de mediana-baja densidad que se encuentra actualmente en la zona de uso público, debiese tener otra categoría, ya que es más susceptible a una alteración antropogénica. La importancia cartográfica del presente estudio queda demostrada, ya que es la primera oportunidad en la cual se discriminan tipos de bosques de A. araucana y estos se localizan con precisión geo-espacial, a una escala más grande a la existente en el centro-sur de Chile.

En la literatura se describen importantes extensiones de bosques achaparrados de $N$. pumilio asociados a límites arbóreos, condición que se corrobora en los dos tipos de bosques achaparrados cartografiados en el parque, con una superficie total estimada de $3.795,5$ ha, que es equivalente a un $36,26 \%$ de la superficie total estudiada.

\section{CONCLUSIONES}

El relieve abrupto y su propia dinámica generan bosques con distintas cobertura de copa, así como también diferentes densidades alta, media y baja. En este sentido, la aplicación metodológica de clasificación donde se combinaron valores del índice de vegetación de diferencia normalizada y bandas original provenientes de Landsat, permitiendo una alta fiabilidad, como consecuencia de la estrecha dependencia observada entre valores de éste índice con las variables de estructura cobertura de copa y diámetro a la altura del pecho de los bosques de A. araucana. Por su parte, el modelo digital de elevación ayudó a reducir el efecto causado por la sombra. De esta manera, se discriminaron, por primera vez, tipos de bosques con una mayor precisión, a una escala cartográfica más grande a las existentes actualmente para los bosques de A. araucana en el parque nacional Conguillío. Finalmente, se agrega que la cartografía obtenida reporta antecedentes acerca de los tipos de bosques de A. araucana en sectores de difícil acceso y cuya nueva información enriquecen futuros estudios privilegiando así un manejo más apropiado del parque. Del mismo modo, la metodología utilizada puede ser replicada a bosques de A. araucana localizados en otras latitudes de su distribución, donde el relieve sea abrupto, situación que es frecuente en este tipo de ecosistemas boscosos.

\section{AGRADECIMIENTOS}

Damos las gracias al financiamiento otorgado por la Dirección de Investigación de la Universidad de La Frontera, Chile, proyecto DIUFRO-reg N ${ }^{\circ} 120430$; con el cual se efectuó el trabajo de terreno y la adquisición de materiales. A la CONAF que facilitó apoyo logístico. Al programa de becas Erasmus Mundus que permitió una estancia postdoctoral en el extranjero y desarrollar esta investigación.

\section{REFERENCIAS}

Apan A. 1997. Land cover mapping forest rehabilitation planning using remotely-sensed data. International Journal of Remote Sensing 18: 1029-1049.

Beaubien J, J Cihlar, G Simard, R Latifovic. 1999. Land cover from multiple Thematic Mapper scenes using a new enhancement-classification methodology. Journal of Geophysical Research 104(22): 909-920.

Brokaw N, R Lent. 1999. Vertical structure. In Hunter M ed. Maintaining Biodiversity in Forest Ecosystems. New York, USA. Cambridge University Press. p. 373-424.

Campo A, A Marinas, R Garcia-González, D Gómez, M Gartzia. 2004. Relaciones entre NDVI, variables topográficas y vegetación en pastos supraforestales del Pirineo. In C. Conesa ed. Territorio y medio Ambiente. Métodos Cuantitativos y Técnicas de Información Geográfica. Murcia, España. Editorial Universidad de Murcia. p. 131-143.

CONAF (Corporación Nacional Forestal, CL), CONAMA (Comisión Nacional del Medio Ambiente, CL), BIRF (Banco 
Interamericano de Reconstrucción y Fomento). 1999. Catastro y evaluación de recursos Vegetacionales nativos de Chile. 86 p. (Informe Novena Región).

Donoso C. 1981. Tipos forestales de los bosques nativos de Chile. Investigación y desarrollo forestal. Santiago, Chile. CONAF/ PNUD/ FAO. 70 p. (Documento de trabajo No 38).

Fitzpatrick-Lins K. 1981. Comparison of sampling procedures and data analysis for a land-use and land-cover map. Photogrammetric Engineering and Remote Sensing 47(3): 343351.

Franklin SE. 1994. Discrimination of subalpine forest species and canopy density using digital CASI, SPOT PLA and Landsat TM data. Photogrammetric Engineering and Remote Sensing 60: 1233-1241.

Giannetti F, L Montanarella, R Salandin. 2001. Integrated use of satellites images, DEMs, soil and substrate data in studying mountainous lands. International Journal of Applied Earth Observation and Geoinformation 3: 25-29.

Gilabert M, J González-Piqueras, J García-Haro. 1997. Acerca de los índices de Vegetación. Revista de Teledetección 8: 35-45.

Grossman YL, SL Ustin, S Jacquemoud, EW Sanderson, G Schmuck, J Verdebout. 1996. Critique of stepwise multiple linear regression for the extraction of leaf biochemistry information from leaf re-flectance data. Remote Sensing of Environment 56: 182-193.

Hall RJ, RS Skakum, EJ Arsenault, BS Case. 2006. Estimating stem volume and basal area in forest compartments by combining satellite image data with field data. Forest Ecology and Management 225: 378-390.

Hudson WD, CW Ramn. 1987. Correction formulation of the kappa coefficient of agreement. Photogrammetric Engineering and Remote Sensing 53: 421-422.

Jakubauskas ME. 1996. Thematic Mapper characterization of lodgepole pine seral stages in Yellowstone National Park, USA. Remote Sensing of Environment 56: 118-132.

Jakubauskas M, K Price. 1997. Empirical Relationships between Structural and Spectral Factors of Yellowstone Londgepole Pine Forests. Photogrammetric Engineering and Remote Sensing 63: 1375-1381.

Landis J, GG Koch. 1977. The measurements of observer agreement for categorical data. Biometrics 33(3): 159-179.

Liberti M, T Simoniello, MT Carone, R Coppola, M D’Emilio, M Macchiato. 2009. Mapping badland areas using LANDSAT TM/ETM satellite imagery and morphological data. Geomorphology 106(3-4): 333-343.

Lu D, P Mausel, E Brondízio, E Moran. 2004. Relationships between forest stand parameters and Landsat TM spectral responses in the Brazilian Amazon Basin. Forest Ecology and Management 198: 149-167.

Lu D. 2005. Integration of vegetation inventory data and Landsat TM image for vegetation classification in the western Brazilian Amazon. Forest Ecology and Management 213: 369-383.

Meyer P, I Klaus, T Kellemberger, T Sandmeier. 1993. Radiometric corrections of topographically induced effects on Landsat TM in an Alpine environment. ISPRS Journal of Photogrammetry and Remote Sensing 48(4): 7-28.

Riaño D, E Chuvieco, J Salas, I Aguado. 2003. Assessment of different topographic corrections in Landsat-TM data for Mappinh Vegetations Types. IEEE Transactions on Geoscience and Remote Sensing 41(5): 1056-1061.

Salas C, L Ene, N Ojeda, H Soto. 2010. Métodos estadísticos paramétricos y no-paramétricos para predecir variables de rodal basados en Landsat ETM+: una comparación en un bosque de Araucaria araucana en Chile. Bosque 31(3): 179-194.

Salovaara KJ, S Thessler, RN Malik, H Tuomisto. 2005. Classification of Amazonian primary rain forest vegetation using Landsat ETM+ satellite imagery. Remote Sensing of Environment 97(1): 39-51.

Sebem E, C González, R García, R de la Vega, A Valverde. 2005. Aportación del NDVI y los sistemas expertos en la mejora de la clasificación temática de imágenes multiespectrales. Anais XII Simpósio Brasileiro de Sensoriamento Remoto. Goiânia, Brasil. 16-21 abril, INPE. p. 2763-2771.

Segura R, G Trincado. 2003. Cartografía digital de la Reserva Nacional Valdivia a partir de imágenes satelitales Landsat TM. Bosque 24(2): 43-52.

Sesnie SE. 2008. SRTM-DEM and landsat ETM+ data for mapping tropical dry forest cover and biodiversity assessment in Nicaragua. Revista Geográfica Académica 2(2): 53-65.

Sesnie SE, PE Gessler, B Finegan, S Thessler. 2008. Integrating Landsat TM and SRTM-DEM derived variables with decision trees for habitat classification and change detection in complex neotropical environments. Remote Sensing of Environment 112(5): 2145-2159.

Shupe SM, SE Marsh. 2004. Cover- and density-based vegetation classifications of the Sonoran Desert using Landsat TM and ERS-1 SAR imagery. Remote Sensing of Environment 93(1-2): 131-149.

Solans JP, P Barbosa. 2010. Post-fire vegetation regrowth detection in the Deiva Marina region (Liguria-Italy) using Landsat TM and ETM+ data. Ecological Modelling 221(1): 75-84.

Wright C, A Gallant. 2007. Improved wetland remote sensing in Yellowstone National Park using classification trees to combine TM imagery and ancillary environmental data. Remote Sensing of Environment 107(4): 582-605. 
